\title{
Electrochemical in vitro Properties of 316L Stainless Steel for Orthodontic Applications
}

\begin{abstract}
NICOLETA SIMIONESCU, ANCA RAVOIU, LIDIA BENEA*
Dunarea de Jos University of Galati, Faculty of Engineering, Research (Competence) Center: Interfaces-Tribocorrosion and Electrochemical Systems (CC-ITES), 47 Domneasca Str., 800008, Galati, Romania

316 Stainless steels are widely used in biomedical applications with respect to their excellent corrosion resistance, nonmagnetic properties, high ductility and acceptable biocompatibility. There have been made electrochemical studies in-vitro in order to determine the corrosion reactions, which are necessary for foreseeing the behavior of the materials used in orthodontic applications. The degradation of metals and alloys in the human body is a combination of effects due to corrosion and mechanical activities. In dentistry, 316L stainless steel are used in a variety of applications: sterilized instruments, endodontic files in root canal therapy, metal posts in root canal treated teeth, temporary crowns, arch wires and brackets in orthodontics, a necessary condition for these applications must to resist to pitting corrosion. The pitting corrosion can be observed only in the case of passivable steels and in the presence of halogen or sulphur ions, in saline or acidic media like the human body. This type of corrosion propagates under the form of small pits, which give off to a significant quantity of metal ions, being very dangerous to the body. The metal ions resulted from the corrosive processes have allergic, carcinogenic and cytotoxic effects. The aim of this work was to evaluate the corrosion behavior of $316 \mathrm{~L}$ stainless steel immersed in two artificial saliva solutions. The electrochemical measurements such as: Open Circuit Potential (OCP), Linear Polarization Resistance (LRP), and Electrochemical Impedance Spectroscopy (EIS), methods were used to fulfill the corrosion evaluation. The research work concludes that the increase of the $\mathrm{pH}$ with a higher concentration of chloride contents lead to a lowest corrosion resistance while a decrease of the $\mathrm{pH}$ with a lowest concentration of chlorides contents reveals a higher corrosion resistance.
\end{abstract}

Keywords: Corrosion reactions, orthodontic, stainless steel 316L, electrochemical studies

The demand for safe and effective materials increased considerably in biomedical engineering due to the growth annual population world's, the increasing numbers of older people and high functional demands of younger people [1]. The basic requirement of a biomaterial is that the material and the surrounding physiological environment should coexist without having any undesirable effect on one another [2].

The stainless steel is a frequently used biomaterial for medical equipment, cranial plates, orthopedic, dental implants, spinal rods, stents and others, due to the favorable combination of mechanical properties, corrosion resistance and cost effectiveness when compared to other metallic implant materials [3]. In dentistry they are used in a variety of applications (sterilized instruments, endodontic files in root canal therapy, metal posts in root canal treated teeth, temporary crowns, arch wires and brackets in orthodontics) [4]. It is already known that the corrosion resistance of stainless steels relates to the formation and breakdown of passive film on the metal surface in the chloride ions solutions. Generally, the pitting potential decreases and corrosion rate increases significantly with increasing the chloride concentration [5].

In recent decades, there has been a significant increase in the number of studies that examined the corrosion properties of 316L stainless steel used in medical applications. In some recent studies, corrosion mechanisms of 316L stainless steel have been examined in various solutions, including different artificial saliva [69].

The purpose of this study was to evaluate the corrosion resistance of 316L stainless steel exposed in two artificial saliva solutions with different $\mathrm{pH}$ and chloride contents in view of orthodontic applications.

\section{Experimental part \\ Materials and methods}

The corrosion experiments were performed on 316L stainless steel medical grade. The chemical composition of $316 \mathrm{~L}$ stainless steel is presented in table 1.

In order to asses the corrosion behavior of 316 $\mathrm{L}$ stainless steel a conventional three-electrode cell was used, consisting of: the working electrode (WE) made of 316L stainless steel, a $\mathrm{Ag} / \mathrm{AgCl}$ reference electrode with $\mathrm{KCl}$ saturated solution ( $E=+199 \mathrm{mV}$ vs. standard hydrogen electrode -SHE) and a Pt-Rh grid as auxiliary electrode. Before corrosion experiments, the squares specimens for electrochemical measurements were connected to a copper wire for electrical connection and insulated with epoxy resin leaving a working area of $2.25 \mathrm{~cm}^{2}$. The working surface was cleaned with alcohol and acetone and rinsed with distilled water.

The corrosion experiments were done using a Potentiostat-Galvanostat PGZ 100 and the data were recorded with VoltaMaster4 software. The electrochemical measurements such as Open Circuit Potential (OCP),

\begin{tabular}{|c|c|c|c|c|c|c|c|}
\hline Element $/ \%$ & $\mathbf{C}$ & $\mathbf{C r}$ & $\mathbf{N i}$ & $\mathbf{M o}$ & $\mathrm{Si}$ & $\mathbf{M n}$ & $\mathbf{F e}$ \\
\hline 316L & 0.03 & $16.5-18.5$ & $11-14$ & $2.0-2.5$ & 1.0 & 2.0 & Balance \\
\hline
\end{tabular}

Table 1

THE CHEMICAL COMPOSITION OF 316L STAINLESS STEEL (wt \%) 
Linear Polarization Resistance (LRP), and Electrochemical Impedance Spectroscopy (EIS) were carried out to access the anticorrosive characteristics of the $316 \mathrm{~L}$ stainless steel medical grade.

The OCP measurements were monitored with the exposure time of one hour, until has been obtained a stable potential vs. $\mathrm{Ag} / \mathrm{AgCl}$ reference electrode.

Linear Polarization Resistance was polarized with a small overvoltage in the range of $\pm 40 \mathrm{mV}$ vs. OCP, at a scan rate $1 \mathrm{mV} / \mathrm{s}$, determining 10 cycles, step duration 0.5 sec and step amplitude $0.5 \mathrm{mV}$.

EIS measurements were performed in the frequency range between $100 \mathrm{kHz}$ and $25 \mathrm{mHz}$, with an $\mathrm{AC}$ sine wave amplitude of $10 \mathrm{mV}$, frequency per decade: $10 \mathrm{~Hz}$ and delay before integration $0.1 \mathrm{~s}$. The electrochemical impedance spectroscopy diagrams were recorded after $60 \mathrm{~min}$ of immersion.

All the recorded impedance spectra were analyzed as Nyquist and Bode representations of diagrams. The obtained data were recorded using ZView software and each experiment was repeated three times to check the reproducibility.

Corrosion tests were performed for stainless steel 316L in Ringer's solution [10] and Fusayama Meyer saliva [11]. The chemical composition of these artificial saliva solutions it is shown in table 2.

Table 2

CHEMICAL COMPOSITION OF ARTIFICIAL SALIVA SOLUTIONS

\begin{tabular}{|l|l|c|c|}
\hline Nr. Crt. & Compound & $\begin{array}{c}\text { Ringer } \\
\text { g/L }\end{array}$ & $\begin{array}{c}\text { Saliva Fusayama Meyer } \\
\mathbf{g} / \mathbf{L}\end{array}$ \\
\hline 1. & $\mathrm{NaCl}$ & 8.402 & 0,4 \\
\hline 2. & $\mathrm{KCl}$ & 0.302 & 0,4 \\
\hline 3. & $\mathrm{CaCl}$ & 0.298 & 0,8 \\
\hline 4. & $\mathrm{NaH}_{2} \mathrm{PO}_{4}$ & - & 0,79 \\
\hline 5. & $\mathrm{UREA}$ & - & 1 \\
\hline 6. & $\mathrm{pH}$ & 6.6 & $\mathbf{5}$ \\
\hline
\end{tabular}

In table 3 are shown the physico-chemical characteristics of these artificial saliva solutions which have been measured with a multi-parameter analyzer CONSORT C 533.

Table 3

ARTIFICIAL SALIVA SOLUTIONS CHARACTERISTICS

\begin{tabular}{|c|c|c|c|}
\hline Simulated Body Fluids & $\mathbf{p H}$ & $\begin{array}{c}\text { Salinity } \\
{[\%]}\end{array}$ & $\begin{array}{c}\text { Conductivity } \\
{[\mathrm{mS}]}\end{array}$ \\
\hline Ringer & 6.6 & 7.8 & 13.7 \\
\hline Fusayama Meyer & 5 & 1.3 & 2.52 \\
\hline
\end{tabular}

\section{Results and discussions}

Open circuit potential (OCP)

The open circuit potential measurements indicate the tendency of a material to electrochemical oxidation in a corrosive environment. The potential time measurements of 316L stainless steel immersed in Fusayama Meyer and Ringer's solutions are shown in figure 1. The open circuit potential was monitored for $60 \mathrm{~min}$ in order to reach the steady state values, for stainless steel surfaces in both artificial saliva solutions.

From figure 1 it can be seen that 316L stainless steel immersed in Fusayama Meyer saliva, showed a slow decreasing value of open circuit potential in the more negative (active) direction, having at the end of $60 \mathrm{~min}$. the value $+89.75 \mathrm{mV}$ vs. $\mathrm{Ag} / \mathrm{AgCl}$, compared with the initial immersion time value of $+132.75 \mathrm{mV}$ vs. $\mathrm{Ag} / \mathrm{AgCl}$.

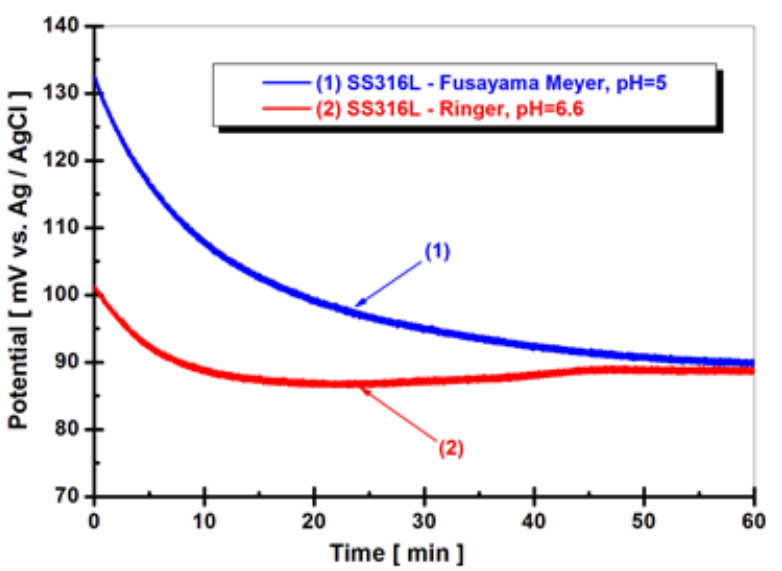

Fig. 1. Open circuit potential plots of the $316 \mathrm{~L}$ stainless steel immersed in: (1) Fusayama Meyer saliva and (2) Ringer's solution during 60 min of immersion time

Oppositely the open circuit potential of $316 \mathrm{~L}$ stainless steel immersed in Ringer solution show a decreasing value from $+101.44 \mathrm{mV}$ vs. $\mathrm{Ag} / \mathrm{AgCl}$ at initial immersion time to $+88.44 \mathrm{mV}$ vs. Ag / AgCl at the end of measurement.

The decreasing trend of potential in both artificial saliva solutions can be attributed to the presence of chloride ions. This behavior indicates the more instability and a degradation of the passive film formed on steel surface.

Also it can be seen that by the end of the experiment a steady state potential is attained for $316 \mathrm{~L}$ stainless steel immersed in both artificial saliva solutions. Comparing the initial values of potential for the $316 \mathrm{~L}$ stainless steel, immersed in Fusayama Meyer and Ringer's solutions, it is clearly revealed that, the first one solution allow to achieve a more ennobled potential in comparison with Ringer's solution.

\section{Linear polarization resistance}

Linear polarization resistance monitoring is an effective electrochemical method of measuring corrosion which allows determining almost instant the corrosion rate. For this method the $316 \mathrm{~L}$ stainless steel was polarized with a small overvoltage in the range of $\pm 40 \mathrm{mV}$ vs. OCP, relative to its open circuit potential and the resulting (linear) current response was measured. The linear polarization resistance measurements were carried out at a scan rate of $1 \mathrm{mV} /$ $\mathrm{sec}$. The resulting of polarization resistance values of 316L stainless steel immersed in the both studied artificial saliva solutions are shown in figure 2 .

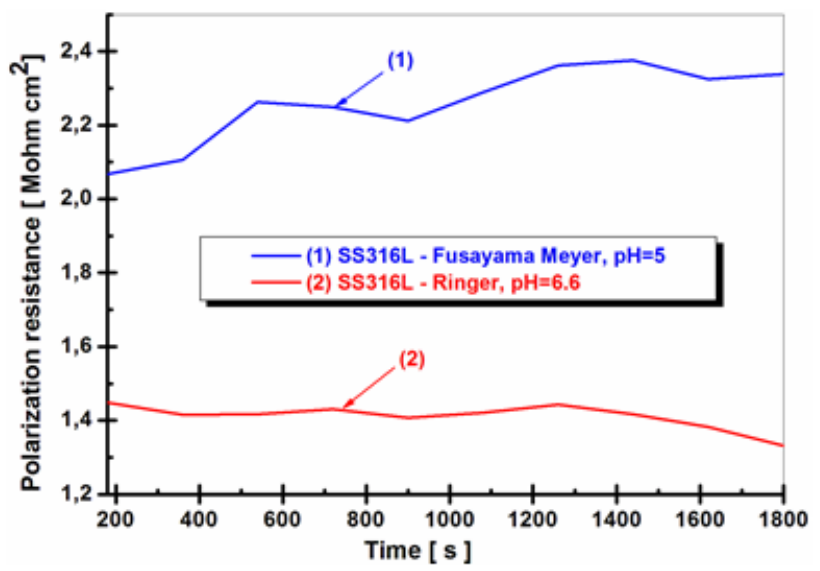

Fig.2. The evolution of polarization resistance (Rp) values of the 316L stainless steel immersed in: (1) Fusayama Meyer and (2) Ringer's solution 
From figure 2 it can be seen that the lowest polarization resistance value is attained by the $316 \mathrm{~L}$ stainless steel immersed in Ringer's solution being equal to $1.41 \mathrm{Mohm}$ $\mathrm{cm}^{2}$, while the $316 \mathrm{~L}$ stainless steel immersed in Fusayama Meyer saliva, reveals a mean value of polarization

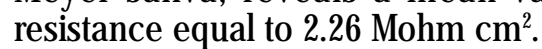

From the polarization diagram, quantitative information on the polarization resistance and corrosion currents can be extracted from the curve slope according to the SternGeary equation [12].

$$
i_{c o r}=\frac{B}{R p}
$$

While the Stern-Geary parameter B was calculated using equation:

$$
B=\frac{b_{a}\left|b_{c}\right|}{2.303\left(b_{a}+\left|b_{c}\right|\right)}
$$

were: $i_{-1}=$ corrosion current density; $R_{n}=$ polarization resistance; $B_{a}$ and $B_{c}$ are the Tafel slopes for anodic and cathodic reactions.

The increase of polarization resistance means the decrease of corrosion current, therefore the decrease of corrosion rate.

The measured resistance is inversely related to the corrosion rate as penetration rate. An increased value of polarization resistance for $316 \mathrm{~L}$ stainless steel immersed in Fusayama as penetration rate, in comparison with 316L stainless steel immersed in Ringer's solution as it can be seen in figure 3 .

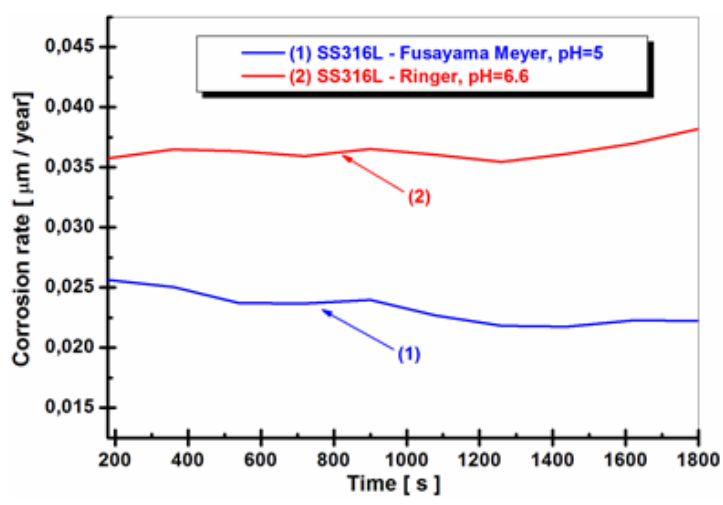

Fig.3. The evolution of corrosion rate as penetration rate values of the 316L stainless steel immersed in: (1) Fusayama Meyer and

(2) Ringer's solutions

From figure 3 it can be seen that the lowest corrosion rate as penetration rate value is attained by $316 \mathrm{~L}$ stainless steel immersed in Fusayama Meyer saliva being equal to $0.023 \mu \mathrm{m} /$ year, while the $316 \mathrm{~L}$ stainless steel immersed in Ringer's solution reveals a mean value of corrosion rate equal to $0.036 \mu \mathrm{m} /$ year.

\section{Electrochemical impedance spectroscopy}

Electrochemical impedance spectroscopy measurements (EIS) is a non-destructive technique were performed to characterize the corrosion behavior of 316L stainless steel immersed in the both tested artificial saliva solutions, namely Fusayama Meyer and Ringer's solution.

The impedance data were displayed in the form of a Nyquist plot. Figure 4(a) shows the electrochemical impedance spectra (EIS) in the form of a Nyquist plot of the 316L stainless steel in both tested solutions. The specific resistance of 316L stainless steel immersed in Ringer's solution is very small comparatively with $316 \mathrm{~L}$ stainless steel immersed in Fusayama Meyer saliva therefore it was necessary to present in figure $4($ b) a zoom of diagrams from figure 4(a), to show the experimental and fitted data for 316L stainless steel immersed in Ringer's solution.

The diagrams were fitted very well also for Bode representations of EIS data as module $Z$ versus logarithm of frequency and phase angle versus logarithm of frequency as they are shown in figure $5(a)$ and (b).

From Nyquist representation of the electrochemical impedance spectroscopy data (fig. 4) it is shown frequency dispersion generally attributed to a capacitance dispersion' expressed in terms of a constant-phase element (CPE). The time constant dispersion was attributed to capacity dispersion or to capacity change with frequency. It was considered the following equation for $\mathrm{CPE}$ and impedance in order to evaluate the electrical equivalent circuit of $316 \mathrm{~L}$ stainless steel immersed in both artificial saliva solutions studied, namely Fusayama Meyer and Ringer's solution [1315]:

$$
Z_{\mathrm{CPE}}=\frac{1}{Q(j \omega)^{\alpha}}
$$

where $Q$ is the frequency-independent real constant of the $\mathrm{CPE}$ in $\mathrm{F} \mathrm{cm}^{-2}, \omega$ is the angular frequency $(2 \pi f)$ in rad s-1, $f$ is frequency $\mathrm{Hz}, j$ is the imaginary number, $j=\sqrt{-1}, \alpha$ is related to the angle of rotation of a purely capacitive line on the complex plane plots. The value of $\alpha$ is associated to the non-uniform distribution of current as the result of surface inhomogeneity (roughness, structure, defects). The parameter $\alpha$ can takes values from -1 to 1 [14]. The CPE has been considered to represent a circuit parameter with limiting behavior as a capacitor for $\alpha=1$, a resistor for $\alpha$ $=0$, and an inductor for $\alpha=-1$ [15]. When $\alpha \neq 1$ the system exhibit behavior that has been assigned to surface heterogeneity or to continuously distributed time constants for charge-transfer reactions [16].

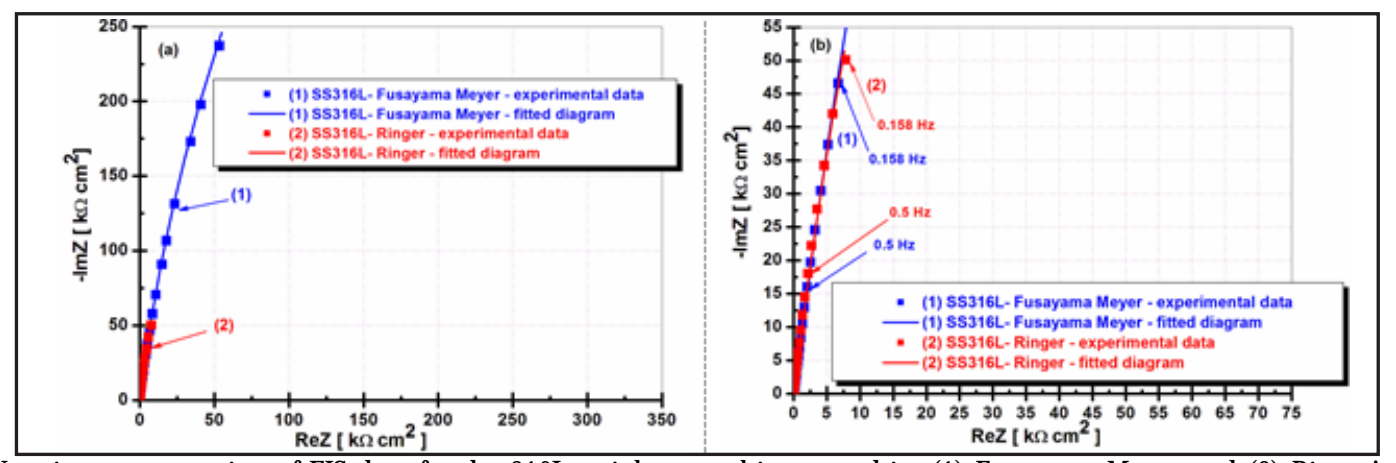

Fig. 4. Nyquist representation of EIS data for the 316L stainless steel immersed in: (1) Fusayama Meyer and (2) Ringer's solutions. (a) Experimental data and fitted diagrams (b) zoom of Nyquist representation to show the diagram of 316L stainless steel immersed in Ringer's solution 

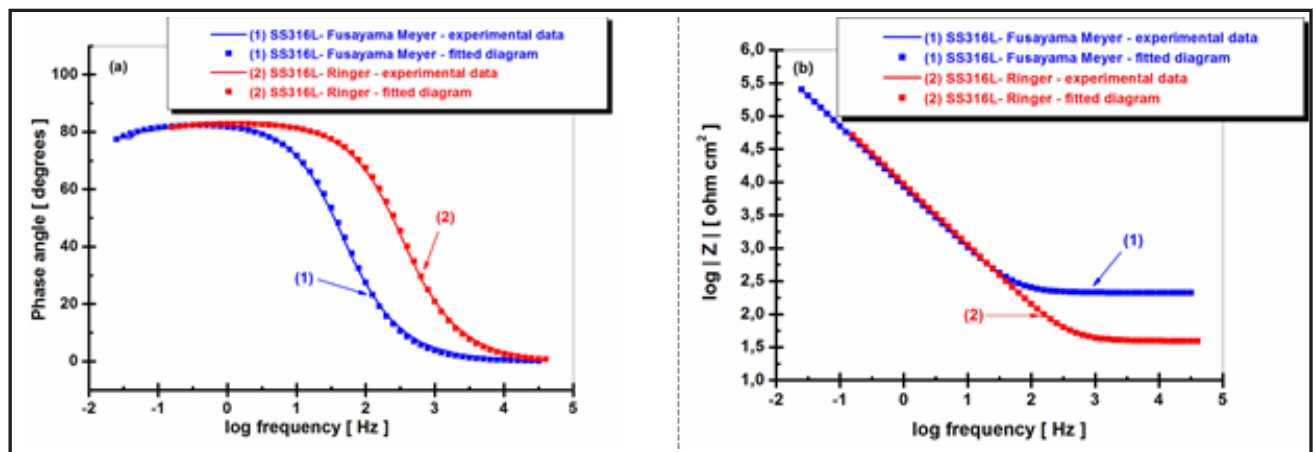

Fig. 5. Bode representation of

EIS data for the 316L stainless steel immersed in: (1)

Fusayama Meyer and (2)

Ringer's solutions. (a) phase angle versus logarithm of

frequency (b) module $Z$

versus logarithm of frequency

Table 4

VALUES FOR THE DIFFERENT ELEMENTS OF THE ELECTRIC EQUIVALENT CIRCUITS WHOSE RESPONSE FITTED THE DATA OBTAINED FOR THE 316L STAINLESS STEEL SURFACE, EVALUATED

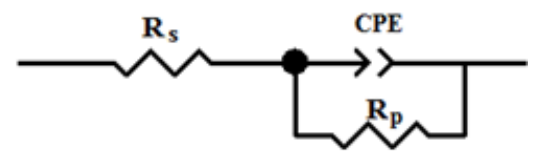
FROM EIS IN SALIVA SOLUTIONS

Fig. 6. Schematic representation of equivalent electric circuits of $316 \mathrm{~L}$ stainles steel surfaces for fitting and simulation of electrochemical impedance spectroscopy experimental data

\begin{tabular}{|c|c|c|}
\hline Elements of the electric equivalent circuits & Fusayama Meyer saliva & Ringer's solutions \\
\hline $\operatorname{Rs}\left(\Omega \mathrm{cm}^{2}\right)$ & 211.2 & 39.25 \\
\hline $\mathrm{CPE}\left(\mathrm{F} \mathrm{cm}^{-2}\right)$ & $0.216 \times 10^{-6}$ & $0.192 \times 10^{-6}$ \\
\hline$\alpha$ & 0.926 & 0.926 \\
\hline $\operatorname{Rp}\left(\mathrm{M} \Omega \mathrm{cm}^{2}\right)$ & 2.44 & 1.71 \\
\hline
\end{tabular}

In order to appreciate the polarization resistance (Rp) it was necessary the fitting of the impedance experimental results by using the equivalent circuits considering a solid electrode (316L stainless steel) in contact with artificial saliva solutions [17-18].

The fitted data were obtained with the equivalent circuits presented in figure 6 , where Rs is the solution resistance, CPE is the constant phase element and $\mathrm{Rp}$ is the polarization resistance.

Tables 4 shown the values obtained for the different elements of the electric equivalent circuits used to fit the electrochemical impedance specters for $316 \mathrm{~L}$ stainless steel surface immersed in artificial saliva solutions.

In table 4, Rs is solution resistance, Rp and CPE are the polarization resistance and the constant phase element, associated to the compact oxide layer and $\alpha$ parameter is related to the rotation angle which calculated impedance response [16].

According to table 4 , the $<$ parameter for $316 \mathrm{~L}$ stainless steel surface immersed in Fusayama Meyer saliva and Ringer solutions is 0.926 near to one and therefore closes to a pure capacitive behaviour. Also remark from the table 4 for polarization resistance (Rp) a higher values attained for $316 \mathrm{~L}$ stainless steel immersed in Fusayama Meyer saliva and a lowest values attained for 316 L stainless steel immersed in Ringer's solution, this decreasing values for $316 \mathrm{~L}$ stainless steel immersed in Ringer solutions is possible due to the presence of a higher concentration of chloride contents in comparison with Fusayama Meyer saliva. This behavior is in good agreements with the previously electrochemical measurements.

\section{Conclusions}

The paper present the corrosion behavior of $316 \mathrm{~L}$ stainless steel in two artificial saliva solutions, namely Fusayama Meyer and Ringer's solution with different $p \mathrm{H}$ values and chlorides content by electrochemical methods, in view of orthodontic applications.

The interpretation of open circuitpotential results reveals that Fusayama Meyer saliva allow to achieve a more ennobled steady state potential of $316 \mathrm{~L}$ stainless steel in comparison with Ringer's solution.

Polarization resistance values obtained by linear polarization, of the $316 \mathrm{~L}$ stainless steel immersed in Fusayama Meyer saliva shows a double value as compared with 316L stainless steel immersed in Ringer's solution and consequently a lower corrosion rate expressed as penetration rate.

The result of the electrochemical impedance spectroscopy measurements which was fitted with a simple equivalent circuit, reveal that the $316 \mathrm{~L}$ stainless steel immersed in Fusayama Meyer saliva present a higher value of polarization resistance which describes a more protective passive film as compared with Ringer's solution which have a lowest value of polarization resistance.

The research work concludes that the increase of the $\mathrm{pH}$ with a higher concentration of chloride contents lead to a lowest corrosion resistance while a decrease of the $\mathrm{pH}$ with a lowest concentration of chlorides contents reveals a higher corrosion resistance.

\section{References}

1. ANDERSON, J. M., Annu. Rev. Mater. Res., 31, 2001, p. 81.

2. NOURI, A., WEN, C., Surface Coating and Modification of Metallic Biomaterials, 94, Woodhead Publishing, WEN, C., United Kingdom, 2015, p. 3-60.

3. FROSCH, K,-H., STURMER, K,-M., Eur. J. Trauma., 32, no. 2, 2006, p. 149.

4. MARDARE, E., BENEA, L., BOUNEGRU, I., Fascicle IX. Metallurgy and Materials Science., no. 1, 2013, p. 68.

5. XIN, S. S., LI, M. C., Corros. Sci., 81, 2014, p. 96.

6. TODERASCU, G., DUMITRACU, V., BENEA, L., CHIRIAC, A., Fascicle IX. Metallurgy and Materials Science., no. 4, 2015, p. 15.

7. HAYES, A., SHARIFI, S., STACK, M. M., J. Bio \& Tribo-Corros., 1, 2015, p. 1.

8. SAMIDE, A., BIBICU, I., OPREA, B., CIOATERA, N., CIUCIU, A., Optoelectron. Adv. Mat., 10, no. 6, 2008, p. 1431.

9. JIANG, R., WANGA, Y., WENB, X., CHENB, C., ZHAOA, J., Appl. Surf. Sci., 412, 2017, p. 214.

10. BERRADJA, A., BRATU, F., BENEA, L., WILLEMS, G., CELIS, J,-P., Wear., 261, 2006, p. 987. 
11. BENEA, L., MARDARE, E., MARDARE, M., CELIS, J ,-P., Corros. Sci., 80, 2014, p. 331

12. CiUbotariU, A. C., BenEA, L., PONTHIAUX, P., Arab. J. Chem., 2016, http://dx.doi.org/10.1016/j.arabjc.2016.07.002.

13. DUMITRASCU, V. M., BENEA, L., Rev. Chim. (Bucharest), 68, no. 1, 2017, p. 77.

14. BENEA, L., DANAILA, E., PONTHIAUX, P., Corros. Sci., 91, 2015, p. 262.

15. SOLTANI, N., TAVAKKOLI, N., KHAYATKASHANI, M., JALALI, M. R. MOSAVIZADE, A., Corros. Sci., 62, 2012, p. 122.
16. HUANG,V. M,-W., VIVER, V., FRATEUR, I., ORAZEM, M. E., TRIBOLLET, B., J. Electrochem. Soc.,154, no. 2, 2007, p. C89.

17. MATEI, M. N., EARAR, K., TRINCA, L. C., MARECI, D., FOTEA, L., PEPTU, C. A., BICA, C., Rev. Chim. (Bucharest), 67, no. 4, 2016, p. 800.

18. MATEI, M. N., CHISCOP, I., EARAR, K., MOISEI, M., MARECI, D., TRINCA, L. C., STAN, T., MUNTEANU C., PACURAR, M., ILIE, M., Rev. Chim. (Bucharest), 66, no. 12, 2015, p. 2009.

Manuscript received: 14.12 .2018 